\title{
Beleza e corpo \\ no De Architectura \\ de Vitrúvio: \\ uma questão \\ em aberto ${ }^{1}$
}

\section{Mário Henrique Simão D’Agostino*}

\begin{abstract}
Resumo Os estilos de elocução «tenro», «médio» e «elevado», operantes na Retórica e Poética Clássicas, podem fornecer insumos para o entendimento do que historiadores têm assinalado como elementos contraditórios na tessitura do De architectura, escrito pelo arquiteto romano Vitrúvio no último quartel do século I a.C.. A conhecida analogia vitruviana da arquitetura como um corpo bem conformado vem aqui considerada por regimes de compositio possíveis de serem identificados no tratado, a invitar indagações sobre o influxo das noções de belo e sublime na ordenação da obra.
\end{abstract}

Palavras-chave: Tratados, De Architectura, Vitrúvio.

\section{Belleza y cuerpo en De architectura de Vitrúvio: una pregunta abierta}

Resumen Los estilos de expresión "tierno", "medio" y "alto", que operan en la retórica y la poética clásicas, pueden proporcionar insumos para la comprensión de lo que los historiadores han señalado como elementos contradictorios en el tejido de De architectura, escrito por el arquitecto romano Vitruvio en el último cuarto del siglo I a. C. La conocida analogía vitruviana de la arquitectura como un cuerpo bien formado se considera aquí mediante regímenes compositivos que pueden identificarse en el tratado, lo que invita a indagar sobre el influjo de las nociones de bello y sublime en el ordenamiento de la obra.

Palabras clave: Tratados, De Architetura, Vitruvio.

\section{Beauty and Body in the De architectura de Vitrúvio: an open question}

\begin{abstract}
The styles of utterance "tender", "medium" and "high", operating in Classical Rhetoric and Poetics, can provide inputs for the understanding of what historians have pointed out as contradictory elements in the weaving of De architectura, written by the roman architect Vitruvius in the last quarter of the 1st century B.C. The well-known Vitruvian analogy of architecture as a well-shaped body is here considered by compositio regimes that can be identified in the treaty, inviting inquiries about the influx of the notions of beauty and sublime in the ordering of the work.
\end{abstract}

Keywords: Treaties, De Archictetura, Vitruvius. 
A Beleza - externa Platão com a voz e os olhos de Sócrates - pudemos vê-la em todo seu esplendor (...). Aqui, temo-la surpreendido, resplandecendo em sua mais luminosa clareza, pelo mais clarividente dos nossos sentidos. (Fedro, 250 b-d)

estojo dos argumentos sobre o Belo, dois são os lugares mais freqüentados entre os Antigos: pela anamnesis platônica, a beleza é conclamo ao perfeito e, por seu lume, ascese da alma ao divino; recto-verso, porque afeita ao visível, a beleza é pharmakón, droga a oscilar entre a clarividência e a alucinação. Tenhamos em conta o potencial imagético do corpo para as doutrinas antigas sobre o perfazimento do belo nas artes, gregas e romanas. Olores de Afrodite, luzeiros de Narciso, afãs de Hércules, enleios de Helena... são longevos os acenos entre a Beleza e o Corpo, e também seus torpores.

À guisa de convite literário, tenhamos o magistral estudo de Erwin Panofsky, Hércules na encruzilhada (1930), no qual, a partir de Pródico e Xenofonte, seguindo Sófocles, Hesíodo, Cícero, Juliano, o Apóstata, e tantos mais, persegue veredas de uma figuração dual da beleza que finda «em um certo ponto da história e no interior de um certo fermento cultural a identificar a [bela] Virtù com a feiúra» (2010, p. 83).

O locus classicus da imagem da arquitetura como corpo situa-se no livro terceiro do De Architectura, redigido no século I a.C. (1997, III, 1, pp. 237-43), no qual o arquiteto Vitrúvio, avivando palavras e métricas de perfeita complexão corporal colhidas do Cânone de Policleto, estatuário da Atenas de Péricles, compara a unidade orgânica e a harmonia geométrico-proporcional do templo com a figura do homem inscrito no quadrado e no círculo. O Renascimento - sabemos por muitos, mas sobretudo por Rudolf Wittkower - não poupará energias na assimilação da referida imagem àquela do «corpo do mundo» e suas ordens matemáticas, tal como descrita por Platão no Timeu. Memoro os desenhos de Filarete (c. 1460), Francesco di Giorgio (c. 1470), Leonardo (c. 1490), Fra Giocondo (1511), Cesare Cesariano (1521), dentre outros. A referência ao corpo na definição do belo comparece em notórios diálogos do filósofo ateniense, mas, no mais das vezes, com o propósito de comparar a sedução (e sensualismo) da beleza corpórea - i.e. a cosmética - à «adulação» do Sofista, guiada por escusas intenções. No livro segundo da República o filósofo detrata o sofista como aquele que, conforme seus interesses, joga com as aparências e não com o desnudamento da verdade-, aquele que «traça um círculo à [sua] volta, como uma fachada ou frontada [de aspecto encantador], uma imagem da virtude, que arrasta atrás de si a raposa matreira e astuciosa do muito sapiente Arquíloco» (II, 365c).

* Mário Henrique Simão D'Agostino é Arquiteto e Urbanista, Professor da Faculdade de Arquitetura e Urbanismo da Universidade de São Paulo, ORCID <http://orcid.org/00000003-3620-7209>.
Por certo, a figura vitruviana se afasta das invectivas platônicas contra o sofista, alinhando-se à longa tradição de «dignificação» da arte retórica que culmina em Cícero e outros grandes retores romanos. A familiaridade do arquiteto com o léxico da retórica clássica tem sido tema de importantes estudos, sobretudo depois da participação de Louis Callebat no congresso O Projeto de Vitrúvio, realizado na cidade de Roma, em março de 1993, no qual forneceu novos insumos para o viés investigativo mais 
1 Uma primeira versão desta conferência de abertura do Colóquio "Tratados de Arte" - São Paulo, 22-23 abril 2019 (Fundação Ema Klabin) foi apresentada no seminário "O Corpo Humano nas Artes Plásticas e na Arquitetura", organizado por Claudia Valladão, com dossiê publicado pela revista Desígnio, $n^{\circ}$ 3, Annablume Ed., 2005. amplo perseguido sobretudo por John Onians, três anos antes, em Mensageiras de significado: Ordens clássicas na Antiguidade, Idade Média e Renascença (1990). Os compromissos da concepção helênica de beleza com a «unidade orgânica das partes entre si e com o todo», a pouco e pouco, cobravam maior precisão pelos trânsitos abertos entre Retórica e Arquitetura.

Pretendo, aqui, deter-me numa contra-imagem, por assim dizer, da tópica da arquitetura como corpo bene figuratus. Vale dizer: não a contradição dessa «palavra de ordem» dos classicismos, mas, antes, a provável detecção de um ruído no contexto mesmo da narrativa vitruviana. Da ordem e harmonia do corpo humano gregos e romanos inferem dois preceitos, conexos e igualmente válidos para a arquitetura:

1. O conúbio entre utilidade e beleza. «Nenhuma parte do corpo é desnecessária», adverte Cícero no Arte Oratória, «e a sua inteira estrutura é uma obra de arte e não do acaso», palavras que ressoam na tríade vitruviana da firmitas, utilitas e venustas;

2. A pertinência e necessidade do ornamento. Assimilando os estilos tenro, médio e elevado da Oratória aos estilos dórico, jônico e coríntio dos templos, Vitrúvio reitera a distinção ciceroniana entre inventio (própria à estrutura argumentativa) e elocutio (própria à ordem expositiva e a persuasão), na qual a interdependência das partes afigura-se como a da ossatura e suas carnes, ou a do corpo nu e suas vestes. Nos livros terceiro e quarto do De Architectura vem detalhada a assimilatio da coluna dórica com o corpo masculino, da jônica com o corpo feminino matronal e da coríntia com o da virgem nubente, ornamentos do decoro arquitetônico: «a posição intermediária do [ornato] jônico colocar-se-á em equilíbrio seja com a severidade do dórico seja com a delicadeza do coríntio.» (De Arch., I, 2)

Precisarei à frente nuanças peculiares a este segundo preceito. Tenhamos por ora o primeiro, mais holístico. De seu ponto de vista, a excelência da beleza tem por metro a conveniência (decen, decor): não se computa pelo precioso, pela exorbitância dos gastos ou raridade dos materiais; afere-se pela aptidão, acuro e adequação (1997, I, 2,8, p. 31). Raciocínio similar Vitrúvio desenvolve para a pintura. Mais: a moléstia e derrogo da pintura afiançam a corrupção da arquitetura: «Quem dera fizessem os deuses imortais voltar à vida Licino e corrigir essa insensatez e os desvios em voga nas nossas pinturas parietais! Mas não será fora de lugar explicar por qual motivo um estilo baseado na ficção ( ratio falsa) prevaleça sobre o critério do verossímil. O fato é que aquele resultado que os antigos, despendendo fadiga e energia, se esforçavam por tornar apreciável graças à habilidade técnica, agora se obtém graças às cores e à sua elegância toda exterior, e o prestígio que o fino trabalho do artista conferia às obras agora é assegurado pela despesa sustentada pelo comitente» (1997, VII, 5, 7, p. 1047).

Irracionalidade igual anuncia-se na arquitetura com a transferência de motivos de um entablamento a outro e com o fausto (1997, I, 2, 6, p. 29-30). Como antídoto, a observância do verdadeiro, a destreza, o esmero, a elegância da feitura. Estes os atributos apreciados pelos Antigos e, enfatiza Vitrúvio, «majoravam o valor dos materiais nobres ao deles se servirem com parcimônia». 
No proêmio ao livro oitavo, o arquiteto deixa patente a convicção de a natureza, copiosa, jamais desprover do necessário. "Pois a inteligência divina», lê-se, "os bens necessários aos humanos não lhes tem feito difíceis de encontrar e custosos como as pérolas, o ouro, o argento e todas aquelas coisas de que nem o corpo nem a natureza desejam, mas tem profusos, oferecendo ao alcance das mãos para todo o mundo, os bens sem os quais a vida dos mortais não está segura.» (1997, VIII, Proem., 3, p.1109) A contraposição do «conveniente» e do «raro», advogada na definição da distributio $(I, 2,6)$, prolonga-se na do «necessário» e do «supérfluo». Trata-se, como mostrou Elisa Romano em A cabana e o templo, publicado em 1987, do professo alinhamento do arquiteto às invectivas contra o luxo lançadas por Catulo e Cícero, dentre outros.

A defesa dos valores morais frente aos efeitos desagregadores da riqueza e do dinheiro modela-se, nos séculos II e I a.C., pelo contraste entre a dignitas do homem honrado e o prestígio resultante da propriedade de bens exteriores. Aos que cuidam da coisa pública convém a gravitas, i.e. rigor moral, honestidade, desinteresse em prol do bem comum, temperança ou autocontrole sobre prazeres momentâneos (abstinentia). Endógenas ao dinheiro são a «libido, luxuria, avaritia, cupiditas, a paixão caprichosa e desenfreada, o prazer desregulado do luxo, a insana sede e cupidez de riqueza» (cf. Romano, 1987, p. 146 e 155). A domus dos grandes homens, ultima o rétor no De Officiis, deve convir ao prestígio do proprietário como um «ornamento para a dignidade»; não atende apenas a exigências do uso, porém previne-se «dos excessos de uma suntuosidade tão faustosa quanto dispendiosa» (cf. Romano, 1994, p.64).

Paradoxalmente, na exposição de Vitrúvio, às advertências contra o suntuoso seguem recomendações para «dar aos edifícios disposições diferenciadas, segundo sejam adequados ao uso dos pais de família ou à riqueza ou à eloqüência (eloquenciae dignitatem)» (Vitruvel, 2, 9, p. 19). O livro sexto amplia a exposição sumária do primeiro. Distinguindo nos edifícios privados as partes reservadas ao uso dos pais de família e as destinadas à visitação pública, o autor elabora uma tipologia na qual o decoro sagra e celebra a estratificação social. Aos que lidam com honras e magistraturas e devem pôr-se ao serviço dos cidadãos, convém «elevados vestíbulos reais, átrios e peristilos assaz amplos, bosques e extensos passeios silvestres condignos à sua majestade», e também bibliotecas, pinacotecas e basílicas «aprestadas de modo não dessemelhante da magnificência das obras públicas, pois nas suas habitações freqüentemente se efetuam deliberações públicas e juízos e arbitragens privadas» (1997, VI, 5, 1-2, p. 845). Ganham pleno contorno as sucintas palavras do livro primeiro sobre o decoro segundo os costumes (id., I, 2, 6, p. 29). A consonância entre o decoro edilício e a excelência do proprietário acolhe, pondo-os lado a lado, a expressão de dignidade e também a de riqueza (ou poder).

Tal adesão a práticas edilícias e estilos de vida consolidados aviva na memória, de imediato, o proêmio a Augusto em louvor da maiestas imperii. Em um e outro caso o aval aos mármores da cidade testemunha o arrebatamento do arquiteto frente à magnificentia das obras. Pierre Gros, num estudo magistral sobre a semântica das ordens no De Architectura, vindo ao lume em 1989, advertirá que as emoções assim acendidas por Vitrúvio parecem discrepar dos sentidos de beleza acalentados por todo o escrito.

As contradições ficam evidentes em duas passagens do tratado. A primeira diz respeito à suntuosidade. Em conclusão ao livro sexto, mencionando as atribuições de praxe que 
competem a comitentes, mestres construtores e arquitetos, Vitrúvio enumera os três aspectos em jogo na apreciação dos edifícios: a habilidade construtiva, a magnificência e a disposição. A responsabilidade da segunda cabe ao proprietário, pois, conforme seus recursos, decide "se construirá obra com tijolos ou cimento ou com cantaria de pedra [lateralícia, cimentícia ou quadrada]». Por outro lado, a especificação dos diferentes materiais a serem empregados na construção, «pelo fato de que em todos os lugares não se formam todos os tipos de materiais», está mais sob a alçada do construtor, de sua «sagacidade», do que do arquiteto. "Se o edifício possuir elegante respeitabilidade (auctoritas) por proporções e relações modulares, a glória será a aura do arquiteto.» Desobrigando o arquiteto de definir os tipos de materiais e a soma dos recursos investidos em magnificência, igualmente acentua que o seu «efeito», exigindo beleza, mede-se sobretudo pelo sumptus, pelo montante despendido. "Quando se aprecia a magnificência, se ela perfaz toda a obra, as despesas serão louvadas por toda autoridade» (1997, VI, 9, 9, p. 859).

A segunda passagem refere ao emprego de materiais nobres na arte. No longo proêmio ao livro sétimo, súmula das obras sobre arte edificatória redigidas por antigos e modernos, o autor finaliza lastimando a ausência de escritos pelos que edificaram obras grandiosas, como Cossuzio, autor do Olimpieion em Atenas, e G. Muzio, cujo Templo de Honra e Virtude «se fosse feito de mármore, de modo a possuir não só refinada arte mas prestígio (auctoritas) pela magnificência e grande despesa, seria mencionado entre as primeiras e supremas obras» (1997, VII, Proem., 17, p. 1027).

Nas duas passagens, Vitrúvio contemporiza com a magnificência e suntuosidade das edificações; pelo reverso, evidencia a sua excisão da «necessidade», "ordem natural» ou, sobretudo nesse caso, "parcimônia» antes admirada na beleza.

Como ajuíza Pierre Gros, no prólogo laudatório a Augusto, engajado em fornecer-lhe regras sólidas sobre uma arte edilícia que aos olhos de todos exclamava com suas pedras a maiestas imperii, o arquiteto finda por anuir a uma política edificatória estranha aos códigos de valores que nutrem a porção mais substanciosa do escrito. "A grandeza do império», exalta Vitrúvio, «também se manifesta no extraordinário prestígio dos edifícios públicos» (1997, I, Proem., 2, p. 11). Em outras passagens do De Architectura Vitrúvio avaliza o uso de colunas soberbas ou da ordem colossal em espaços suntuosos e magnificentes. Os desvios da parcimônia e justa-medida na consecução da beleza coligam-se a mudanças superlativas no modo de ideação do próprio edifício. Rompese, em síntese, a urdidura bem tecida do conceito de unidade orgânica que abre o tratado: na symmetria a coerência entre partes e todo, a harmonia de forma e figura enfeixa-se na coesão corpórea - uno intiero e ben finito corpo, conforme a fórmula consagrada na Renascença. A estese não se desliga do espectador, mas os sentidos que nele acorda tocam ao edifício como um todo. Nesse cosmo, conviria mais falar de «reverência e respeito» do que de «manifestação de poder».

O páthos da magnificência augustana é outro. Envolve o espectador com a sua grandiosidade, capturando-lhe os sentidos. Sua imponência o constrange, suscita contenção, incide sobre ele arrebatando-o (subjugando-o, por assim dizer). Para além da perfeição e esplendor do belo, é do "espanto», da "comoção», do «terror» que irrompe a admiração (támbos e phóbos, no vocabulário grego). Sobretudo, sua arte visa ao exterior, rescinde o corpo coeso da symmetria: cenográfica, espetacular, 
unidirecional - a se sobrepor e como que descurar a tudo o que foge aos olhos. Fictícia, como as pinturas. Urbe e Orbe: nesse universo imperam a auctoritas e maiestas do mármore augustano. "O código de valor ao qual reenviam essas palavras», pondera Gros, «entra dificilmente no quadro definido pela morfologia modular que rege o conjunto dos capítulos consagrados à construção pública, religiosa ou profana. A concepção da arquitetura como manifestação do poder parece funcionalmente estranha a um sistema no qual os critérios da beleza se nutrem de relações internas ao edifício, como a symmetria, a eurythmia, o decor, e do qual parece excluída, por princípio, toda busca de efeito orientado para o exterior» (1989, p. 126).

No volumoso L'architecture romaine, o historiador multiplica exemplos desse novo kunstwollen, como os templos de Vênus Genetriz e Marte Ultor, nos fóruns de Júlio e Augusto respectivamente.

A capacidade de impressionar pela exorbitância, magnificência ou preciosismo, pelo excesso mais que por medida, formas todas de manifestação de poder, finda por acolher, no coração mesmo do estilo elevado, aquela ratio falsa combatida por Vitrúvio como a cicuta das artes. O «fictício», o «ilusório» e o «irracional»- a sobrepujar o esmero pelo «necessário», «útil» e «natural» - fornecem todos armas poderosas para a prossecução dos novos valores da elocutio perseguidos no período tardo-republicano e imperial. Na basílica que o arquiteto edifica em Fano (única de que testifica ser autor), o emprego da ordem colossal «reduz consideravelmente as despesas. As mesmas colunas de altura ininterrupta até as traves da cobertura parecem aumentar seja a magnificência dos recursos seja a autoridade» (1997, V , 1, 10, pp. 555-57).

Mas a alvorada não prenuncia, por certo, o nítido contraste entre as preceptivas próprias ao éthos da simetria e ao páthos do sublime, como cria o romântico inglês nos séculos XVIII e XIX da nossa era; antes, consiste na gêmula de uma concordia discors cuja parábola, perpassando o escrito vitruviano, projeta-se muito além do chamado mundo antigo. À guisa de conclusão, volvamos, uma vez mais, aos expedientes do decoro e à assimilatio acenada por Vitrúvio entre os estilos da oratória - tenro, médio e elevado - e as espécies de colunas - dórica, jônica e coríntia.

Cícero: «Três são os estilos, em cada um dos quais floresceram certos oradores [...] por um lado, os grandiloquentes, por assim dizer, com elevada gravidade de sentenças e grandiosidade de palavras, veementes, variados, abundantes, graves, hábeis e preparados para comover e arrastar os ânimos [...]; por outra parte, os simples, claros, expositores [...] que tudo o faz mais inteligível que magnífico [eu sublinho], polidos em um estilo preciso e conciso [...]. Por sua vez, há um orador intermediário entre esses, e por assim dizer, temperado, que não se serve nem da precisão dos últimos e nem da torrente dos primeiros; [...] partícipe dos dois em honra da verdade [...]» (Orator, 20-21, trad. Karina Fonsaca, p. 196).

A grandiloqüência do estilo elevado não se prende tanto à necessidade e precisão das partes (dos argumentos e ornatos) na ordem expositiva da matéria, «em honra da verdade»; visa, em maior grandeza, exaltar uma idéia, uma proposição, um valor para além da verdade, do certo ou errado, por assim dizer. Eis a sua potência e o seu perigo! Venus-venenum... A unidade e coesão corpórea cumpre-se aí, como ressalva Aristóteles na Retórica, quando aquilo que é exposto não perde sentido, não soçobra 
com o excesso de ornamentos, não derrui com o empolamento estilístico a obnubilar a percepção e enlevo do que é aclamado. No limite extremo, o uno intiero e ben finito corpo precisa ser preservado, ainda que não se ajuste bem à analogia com o ordo do corpo humano, conúbio de firmitas, utilitas e venustas.

Quiçá a Retórica, operante nas artes até o Século das Luzes, forneça a razão maior para que o Perì Hýpsos, a tratativa do Sublime na Antiguidade, não se ponha em contraste com a Beleza, cindindo a estesia - a modalidade de conhecimento própria aos sentidos, como asseverará Baungarten - pelos radicais em claro-escuro da Estética nascente.

\section{Referências bibliográficas}

CALLEBAT, Louis. (1994) "Rhetorique et Architecture dans le De Architecture de Vitruve", In GROS, P. (a cura di) Le Project de Vitruve. Object, destinataires et réception du De Architectura, Acte du colloque international (Rome, 26-27/3/1993). Rome.

CICERONE. (2000) Dell'oratore. Milano: Biblioteca Universale Rizzoli.

(1998) / doveri. Milano: Biblioteca Universale Rizzoli.

(1991) El Orador. Madrid: Alianza.

GROS, Pierre. (1990) L'Architettura Romana. Dagli inizi del IIl secolo a.C. alla fine dell'alto impero. (2001) Milano: Longanesi \& C.

(1989) "L'auctoritas chez Vitruve. Contribution à l'étude de la sémantique des ordres dans le De Architectura", In AA.VV. Munus non ingratum. Proccedings of the International Symposium on Vitruvius' De Architectura and the Helenistic and Republican Architecture. Ed. by H. Geertman \& J.J. d Jong. Leiden.

PANOFSKY, Erwin. (2010) Ercole al bivio e altri materiali iconografici dell'Antichità tornati in vita nell'età moderna. Macerata: Quodlibet Srl.

ROMANO, Elisa. (1987) La Capanna e il Tempio: Vitruvio o dell'Architettura. Palermo: Palumbo Editore.

(1994) "Dal De Officcis a Vitruvio, da Vitruvio a Orazio: il dibattito sul lusso edilizio", In GROS, P. (a cura di) Le Project de Vitruve. Object, destinataires et réception du De Architectura, Acte du colloque international (Rome, 26-27/3/1993). Rome.

VITRUVE. (1989-ss) De L'Architecture. Paris: Les Belles Lettres.

VITRUVIO (1997). De Architettura. Torino: Giulio Einaudi Editore. (A cura di P. Gros. Trad. e commento di A. Corso e E. Romano).

WITTKOWER, Rudolf. Architectural Principles in the Age of Humanism. London: Academy Editions/New York: St. Martin's Press, 1988. 